\title{
Study on Mitochondrial DNA Heteroplasmy from Liver, Kidney and Muscle of Common Carp
}

\author{
Cao ZM, Ding WD, Wang JX and Bing XW
}

Freshwater Fisheries Research Center, Key Laboratory of Freshwater Fisheries and Germplasm Resources Utilization, Ministry of Agriculture, Wuxi, China

${ }^{*}$ Corresponding author: Bing XW, Ph.D. Investigator, Freshwater Fisheries Research Center, Key Laboratory of Freshwater Fisheries and Germplasm Resources Utilization, Ministry of Agriculture, Wuxi, Jiangsu, 214081, China, Tel: 0086-510-85558719, E-mail: bingxw@ffrc.cn

Citation: Cao ZM, Ding WD, Wang JX, Bing XW (2015) Study on Mitochondrial DNA Heteroplasmy from Liver, Kidney and Muscle of Common Carp. J Vet Sci Anim Husb 3(2): 201. doi: 10.15744/2348-9790.1.601

Received Date: January 11, 2015 Accepted Date: April 13, 2015 Published Date: April 15, 2015

\begin{abstract}
Mitochondrial DNA (mtDNA) heteroplasmy has been found to be commonly present in many organisms. However, the studies on the mitochondrial heteroplasmy within group of fishes are currently lacking. This specific purpose of this study was to investigate the mtDNA heteroplasmy in different organs within group of common carp. Based on cytochrome B (cyt B) gene, we amplified in a fragment of cytB gene from three tissues including liver, kidney and muscle of five individuals via polymerase chain reaction (PCR) with Pfu DNA polymerase, sequenced the amplified DNA fragments and compared mitochondrial heteroplasmy among these tissues. The result showed that the mean frequency of wild-type in muscle, liver and kidney was $54.4 \%, 56.8 \%$ and $68 \%$ respectively. Among the point mutations, frequency of substitution of $\mathrm{G}$ for $\mathrm{A}$ and $\mathrm{C}$ for $\mathrm{T}$ is $58.2 \%, 71.4 \%$ and $74.1 \%$ respectively in muscle tissues, liver and kidney. Of total mutations whereas the substitutions of $\mathrm{T}$ for $\mathrm{A}$, $\mathrm{T}$ for $\mathrm{C}, \mathrm{A}$ for $\mathrm{T}, \mathrm{A}$ for $\mathrm{G}, \mathrm{A}$ for $\mathrm{C}, \mathrm{G}$ for $\mathrm{C}, \mathrm{C}$ for $\mathrm{G}, \mathrm{T}$ for $\mathrm{G}, \mathrm{G}$ for $\mathrm{T}$ is $38.0 \%, 26.4 \%$ and $24.2 \%$ of total mutations. The study has shown that mitochondrial heteroplasmy occurred widely in different tissue within groups of carp.
\end{abstract}

Keywords: Mitochondrial DNA heteroplasmy; Carp; Cytochrome B

\section{Introduction}

Mitochondria are the important organelle of fish cells and they are the energy-generating factory within the cells, providing up to $90 \%$ of the energy source in the form of ATP through oxidative phosphorylation. In addition, mitochondria play an important role in program cell death (apoptosis) and necrotic death. Thus, studies on mitochondria are highly significant for our understanding of the growth, development, metabolism, aging, diseases of bio-organisms and biological evolution. Regarding to the studies on mitochondria in fishes, the current studies have mainly focused on utilization of the gene fragments of several mitochondrial DNA (mtDNA)-encoded genes (such as 16S rRNA, COI gene and cytochrome B gene et al.) to investigate the different species of fishes and the evolutionary relationships among different species and different populations of fishes [1-7].

Mitochondrial DNA is a naked, circular molecule that lacks the protection by histones. Furthermore, due to the mutative effects caused by the oxidative oxygen species (ROS) generated by the mitochondrial respiratory chain, mtDNA has relatively high mutation rate and sequence diversity. The mtDNA heteroplasmy usually means the existence of two or more mtDNA subpopulations within a single cell or in one individual. The mtDNA heteroplasmy includes point heteroplasmy and length heteroplasmy. However, the analysis of phylogeny was conducted with mtDNA, these differences in mtDNA heteroplasmy are usually ignored. Lu et al. even thought that a majority of fish mtDNA molecules were of homogeneity and frequency of mtDNA heteroplasmy was very low [8]. This point of view has been widely accepted in current studies on fish mitochondria and thus, many reports about the fish mtDNA heteroplasmy are misunderstood as the differences in mtDNA sequences between different individuals and between different fish populations. However, Kmiec believed that mtDNA heteroplasmy was widely present in animal species [9]. In particularly, there are many reports about the studies on the relationships between mtDNA heteroplasmy and human diseases. The mutations at certain locus of mtDNA (either rearrangement of large DNA fragments or single nucleotide replacement) have been found to be related to human diseases. Because there are many copies of mtDNA molecule within a single mitochondrion, mtDNA heteroplasmy needs to reach certain threshold to cause the pathogenesis of certain diseases [10]. Among the studies on mitochondrial DNA mutations, the most frequently studied mutation is the point mutation of replacement of A with $\mathrm{G}$ at the 3243 locus of dihydrouracil loop of leutRNA gene. This point mutation leads to a MELA subpopulation with mitochondrial encephalopathy or other disease groups. The pathogenic causes of this diseases is the heteroplasmy distribution of this mutation among the mitochondria of skeletal muscles and its proportion relative to total mtDNA has reached to certain threshold [11-13]. 
Cytochrome B is widely used in population genetics of fish, especially in study on phylogenesis relationship among different geographical population. Based on the reports, we found that the gene had certain heterogeneity between different groups, but most of the researches on heterogeneity don't involve that within group, furtherly even within one individual.

Due to the lack of studies on the mitochondrial heteroplasmy in fishes, we are not clear whether mitochondrial heteroplasmy is present within groups of common carp and if so, what is the degree of the mitochondrial heteroplasmy. Thus, we apply Pfu DNA polymerase with high fidelity to amplify part fragment of mtDNA-encoded cytochrome B gene, then clone and sequence 100 clones per tissues to detect heteroplasmy with high sensitivity. The result will provide the basic knowledge for future studies on roles of mitochondrial heteroplasmy in physiological diseases, aging, and degeneration of fishes.

\section{Materials and Methods}

\section{Sources of Materials}

The carp samples were collected at November 2014. Five carp samples were obtained from Central Fish Nursery Farm of Fresh Water Fishery Research Institute of Chinese academy of Fishery Sciences. The carp fish was one-year Cyprinus carpio var Jian. Mitochondrial DNA was isolated from the muscles, liver and kidney.

\section{Isolation of genomic DNA}

About $0.1 \mathrm{~g}$ of muscles, liver and kidney sample of carp was weighted, respectively, and $450 \mu \mathrm{l}$ of STE buffer $(150 \mathrm{mmol} / \mathrm{l} \mathrm{NaCl}$, $50 \mathrm{mmol} / \mathrm{l}$ Tris, $1 \mathrm{mmol} / \mathrm{l} \mathrm{EDTA}, 12.5 \mu \mathrm{l}$ of $10 \%$ SDS and $10 \mu \mathrm{lof}$ protease $\mathrm{K}(20 \mathrm{mg} / \mathrm{ml})$ were added to each sample and mixed well. These samples were digested at $55^{\circ} \mathrm{C}$ overnight and then were abstracted with phenol and chloroform one time each. Equal volume of isopropanol was added to precipitate DNA. The samples were centrifuged at $12000 \mathrm{rpm}$ for $30 \mathrm{~min}$. The pellets were washed with $70 \%$ of ethanol twice and air dried in room temperature. The DNA was dissolved with $30 \mu \mathrm{l}$ of double-distilled water. The quality of the isolated DNA was checked with $0.8 \%$ of agarose gel.

\section{Amplification of a Cytochrome B DNA fragment}

In order to ensure the accuracy of the amplified DNA sequences, Pfu DNA polymerase was used in this study. The primer sequences for amplification of cytochrome B DNA fragment were: the upstream primer sequence 5'-gacttgaaaaccaccgttg- $3^{\prime}$ and the downstream primer 5 '-cctcagaaggatatttgtcctc-3. The total volume of the amplification reaction was $25 \mu \mathrm{l}$, containing $1.0 \mu \mathrm{l}$ DNA template, $2.5 \mu \mathrm{l}$ of $10 \times \mathrm{PCR}$ buffer, $10 \mathrm{pmol}$ each primer, $1.5 \mu \mathrm{l}$ of dNTPs ( $2.5 \mathrm{mmol}), 2 \mathrm{U}$ of Pfu DNA polymerase and brought to $25 \mu \mathrm{l}$ with double distilled water. The procedures for PCR amplification were as follows: the reaction mixture was denatured at $94{ }^{\circ} \mathrm{C}$ for $2 \mathrm{~min}$ first, followed by 35 cycles of denaturation at $94^{\circ} \mathrm{C}$ for 30 seconds, re-annealed at $55^{\circ} \mathrm{C}$ for 30 seconds, and extended at $72^{\circ} \mathrm{C}$ for 45 seconds, and finally extended at $72{ }^{\circ} \mathrm{C}$ for $10 \mathrm{~min}$. The PCR amplified products were checked in $1.0 \%$ of agarose electrophoresis.

\section{Cloning and Sequencing of the Amplified DNA fragment}

Because the Pfu DNA amplified product cannot be directly linked to T vector, we used the ordinary Taq enzyme to catalyze the attachment to its ends. The reaction system volume was $10 \mu \mathrm{l}$, containing $7 \mu \mathrm{l}$ of amplified product, $1 \mu \mathrm{l}$ of $10 \times \mathrm{PCR}$ buffer, $5 \mathrm{U}$ of Taq enzyme, and $0.2 \mathrm{mM}$ dATP. The reaction mixture was incubated at $70^{\circ} \mathrm{C}$ for $30 \mathrm{~min}$, then linked with $\mathrm{T}$ vector and transformed to E. coli strain JM109. About 100 colonies were picked up for each organ sample and digested with restriction enzyme to ensure that the inserted fragment was correct. The DNA was sequenced in Biosune Biotechnology Company.

\section{Sequence analysis}

After eliminating vector DNA sequences from the obtained sequences, the remaining DNA sequence was converted into the FASTA format and analyzed with Bioedit software. For those sequences that could not be compared, the closely related sequences were found out with Blas software from NCBI Database. The consensus sequence (Wild type sequences) and the mutated sequences that were different from the consensus sequence were searched with Bioedit software.

\section{Results}

\section{Sequencing results and consensus sequence (reference sequences)}

In this study, 100 pieces of sequences were obtained for each organ sample and the mean length of each sequence was $468 \mathrm{bp}$. The average sequence length for three organs per one carp (a total of 300 pieces of DNA sequences) was $702000 \mathrm{bp}$. There were average 645 point mutations per one carp (a point mutation that occurred in at least two pieces of DNA sequences was count as two point mutation), accounting for $0.09 \%$ of total DNA sequences examined.

Because the mutations occur in a random manner, we cannot determine which sequence is the wild type sequence, so we assume that each mutation site is individual case, the remaining non mutation sites are the original site. The consensus sequence showed in Figure 1 was taken as wild type sequence. 


\begin{abstract}
GACTTGAAAAACCACCGTTGTTATTCAACTACAAGAACCACTAATGGCA AGCCTACGAAAAACACACCCTCTCATTAAAATCGCTAACGACGCACTAG TTGACCTACCAACACCATCCAACATCTCAGCATGATGAAACTTTGGATC CCTCCTAGGACTATGCTTAATTACCCAAATTTTAACCGGCCTATTCCTAG CCATACACTACACCTCAGACATTTCAACCGCATTCTCATCTGTTACCCAT ATCTGCCGAGACGTAAATTACGGCTGACTAATCCGTAATGTACACGCCA ACGGAGCATCATTCTTCTTCATTTGCATTTACATACACATCGCCCGAGG CCTATACTACGGATCATACCTTTACAAAGAAACCTGAAACATTGGTGTA GTCCTTCTGCTACTAGTCATGATAACAGCCTTCGTTGGCTATGTTCTTC CATGAGGACAAATATCCTTCTGAGG
\end{abstract}

Figure 1: Consensus sequence (reference sequence) of cytochrome B fragment of Carp

\title{
Comparison of the ratios of mutated sequences
}

Table 1 showed that the mean ratio of the wild-type DNA sequence in muscle tissues, liver and kidney was $54.4 \%, 56.8 \%$ and $68 \%$, respectively. The ratio of wild-type DNA sequence in kidney was the highest whereas the ratio of wild-type DNA sequence in muscle tissue was the lowest. The large fragment mutations included deletion, replacement, and relocation of large fragment or defection of primers.

\begin{tabular}{|c|c|c|c|c|c|c|c|}
\hline & \multirow[b]{2}{*}{ Sample } & \multicolumn{2}{|c|}{$\begin{array}{l}\text { Frequency of insertions/ } \\
\text { deletions Large mutation }\end{array}$} & \multicolumn{2}{|c|}{$\begin{array}{c}\text { Frequency of } \\
\text { point mutation }\end{array}$} & \multicolumn{2}{|c|}{$\begin{array}{l}\text { frequency of } \\
\text { wide type }\end{array}$} \\
\hline & & & Mean & & Mean & & Mean \\
\hline \multirow[t]{5}{*}{ Muscle } & 1 & $9 \%$ & $8.4 \%$ & $37 \%$ & $37.2 \%$ & $54 \%$ & $54.4 \%$ \\
\hline & 2 & $11 \%$ & & $36 \%$ & & $53 \%$ & \\
\hline & 3 & $7 \%$ & & $40 \%$ & & $53 \%$ & \\
\hline & 4 & $12 \%$ & & $38 \%$ & & $50 \%$ & \\
\hline & 5 & $8 \%$ & & $35 \%$ & & $57 \%$ & \\
\hline \multirow[t]{5}{*}{ Liver } & 1 & $2 \%$ & $2.6 \%$ & $39 \%$ & $40.6 \%$ & $59 \%$ & $56.8 \%$ \\
\hline & 2 & $3 \%$ & & $42 \%$ & & $55 \%$ & \\
\hline & 3 & $1 \%$ & & $43 \%$ & & $56 \%$ & \\
\hline & 4 & $6 \%$ & & $36 \%$ & & $58 \%$ & \\
\hline & 5 & $1 \%$ & & $43 \%$ & & $56 \%$ & \\
\hline \multirow[t]{5}{*}{ Kidney } & 1 & $1 \%$ & $1 \%$ & $32 \%$ & $31 \%$ & $67 \%$ & $68 \%$ \\
\hline & 2 & $1 \%$ & & $32 \%$ & & $67 \%$ & \\
\hline & 3 & $2 \%$ & & $36 \%$ & & $62 \%$ & \\
\hline & 4 & $1 \%$ & & $30 \%$ & & $69 \%$ & \\
\hline & 5 & $0 \%$ & & $25 \%$ & & $75 \%$ & \\
\hline
\end{tabular}

\section{Comparison of point mutations}

Table 2 showed the comparison of point mutation among muscle, liver and kidney, which indicated that the most frequent alternative point mutation was the replacement of $\mathrm{A}$ with $\mathrm{G}$, followed by the replacement of $\mathrm{C}$ by $\mathrm{T}$. These two alternative replacements counted for $58.2 \%, 71.4 \%$ and $74.1 \%$ respectively in muscle tissues, liver and kidney of total mutations. The ratio of deletion and insertion was relatively low, accounting for only $3.7 \%, 2.2 \%, 1.7 \%$ of total mutations respectively in muscle tissues, liver and kidney. The alternative substitutions of A with T, T with A, G with A,C with A, C with G, G with $C, G$ with $T$ and T with $G$ were the mutations with low frequency, accounting for $38.0 \%, 26.4 \%$ and $24.2 \%$ of total mutations.

\section{Discussion}

There is certain base-pair mismatch frequency when DNA fragment is amplified with Taq polymerase and the base-pair mismatch frequency for ordinate Taq polymerase is $10^{-5}$ base pair per cycle of amplification whereas the base pair mismatch frequency of Pfu DNA polymerase is reduced to the order magnitude of $10^{-6} / \mathrm{cycle}$ of amplification. In the present study, Pfu DNA polymerase was used for amplification of DNA fragment and a total of 645 mutation loci were identified, accounting for $0.09 \%$ of the total DNA sequences examined, among which the ratio of base pair mismatch and the ratio of mutated locus were not at the same order of magnitude. Thus, we believed that the mutated louses are the phenotype of the mitochondrial heteroplasmy. 


\begin{tabular}{|c|c|c|c|}
\hline Type of mutation & Muscle & Liver & Kidney \\
\hline Insertion & 3.6 & 0.8 & 0.4 \\
\hline Deletion & 5.2 & 4.4 & 3.2 \\
\hline Substitution of T with C & 67.4 & 75.6 & 61.8 \\
\hline Substitution of A with G & 74.6 & 89.2 & 67.2 \\
\hline Substitution of A with T & 20.6 & 18.6 & 4.4 \\
\hline Substitution of C with T & 25.6 & 14.2 & 4.2 \\
\hline Substitution of T with A & 21.4 & 8.8 & 13.2 \\
\hline Substitution of G with A & 12.8 & 8.2 & 1.0 \\
\hline Substitution of C with A & 5.2 & 1.2 & 3.2 \\
\hline Substitution of C with G & 4.4 & 0.8 & 5.4 \\
\hline Substitution of G with C & 1.0 & 5.6 & 0.8 \\
\hline Substitution of G with T & 0.4 & 2.2 & 3.8 \\
\hline Substitution of T with G & 0.8 & 1.0 & 5.8 \\
\hline
\end{tabular}

Table 2: Mean frequency of point mutation per one carp among muscle, liver and kidney

Cytochrome B gene is a coding sequence. Because of codon degeneracy, mitochondrial heterogeneity doesn't mean the same mutation frequency of the cytochrome B proteins. In fact, the decrease of the activity of mitochondria should be lower than the increase of heterogeneity. Because of some chronic, accumulating effects of internal and external factors on mitochondria which can trigger aunobvious recession of mitochondrial function, we can't take the activity of the cytochrome B protein as measurement. So we still think that the heterogeneity is an important indication of mitochondrial variation.

In this study, we observed that the mean frequency of wild-type DNA sequences for muscle tissues, liver and kidney was $54.4 \%$, $56.8 \%$ and $68 \%$, respectively. The frequency of wild type DNA sequence in kidney was the highest whereas the frequency of wild type DNA sequence in muscle tissue was the lowest, indicating the mtDNA in muscle tissues is more easily mutated and accumulated, leading to the increased mtDNA heteroplasmy. These results are similar to with those reported by a study on the human mtDNA heteroplasmy [14,15], implying that the mitochondrial functions in muscle cells are relatively poorer. The mitochondrial heteroplasmy in kidney was relatively lower, implying that the mitochondrial functions in kidney cells are relatively good.

The results of this study have demonstrated that the mitochondrial heteroplasmy is not only present in carp mtDNA and the mitochondrial heteroplasmy also differs in different organs of the same individual carp. The formation of mitochondrial heterogeneity is related to the mitosis of cells. When the fertilized eggs display mitochondrial heteroplasmy and the mutated DNA can be inherited then mutated mtDNA can be randomly distributed to their daughter cells during cell division, replication and segregation of the mitochondrial heteroplasmy of the cells can take place during the consecutive cell division, leading to the differences in mitochondrial heteroplasmy among different organs even different cell [16]. Because mtDNA is a naked macromolecule, it is easily mutated by the attack of mitochondrially-derived reactive oxygen species (ROS). These oxidative stressinduced mutations can be easily accumulated in the differentiated cells, leading to increased mitochondrial heteroplasmy. The higher ratio of mitochondrial heteroplasmy in the muscle cells might be closely related to their higher degree of differentiation and the longer exposure to ROS. These results also imply that without appropriate means to repair this mitochondrial heteroplasmy, the muscle tissues of fishes can easily become aging, leading to the decreased moving capability of the fishes with higher age.

Among the point mutations, the replacement of A with $\mathrm{G}$ was the most frequent one, followed by the replacement of $\mathrm{T}$ with $\mathrm{C}$. These two replacements accounted for $58.2 \%, 71.4 \%$ and $74.1 \%$ respectively in muscle tissues, liver and kidney. The replacements of A with T, C with T, T with A, G with A were the point mutations with low frequency. Together, they accounted for only $33.1 \%$, $21.6 \%$ and $13.2 \%$ of the total mutations. The percentage of deletion and insertion was relatively low, accounting for only $3.7 \%$, $2.2 \%, 1.7 \%$ of total mutation whereas the substitutions of $\mathrm{C}$ with $\mathrm{A}, \mathrm{C}$ with $\mathrm{G}, \mathrm{G}$ with $\mathrm{C}$, and $\mathrm{G}$ with $\mathrm{T}$ and $\mathrm{T}$ with $\mathrm{G}$ were the rare mutations. Together, they accounted for $5.0 \%, 4.8 \%$ and $10.9 \%$ of total mutations. These may be due to the reason that transition mutation occurs more easily than transversion mutation does. However, it is puzzled that the frequency of the rare mutations was even higher in kidney in which the frequencies of mtDNA mutations is the lowest.

While mitochondria are the very important organelle of fish cells, the studies on fish mitochondria during recent years were mainly restricted to the investigations on the phylogeny and distinguish of geological populations of fishes. Regarding to the studies on human diseases, it has been found that mitochondrial dysfunctions are closely related to a number of diseases, aging and development of cancers. However, the studies on the relations of mitochondrial dysfunctions with various diseases in fishes are currently lacking. The results of this study have indicated that the phenomenon of mitochondrial heteroplasmy is commonly present within an individual carp. From these results, it is possible to predict the existence of the differences in mitochondrial act- 
ivities among different organs. Whether or not the mutations in mtDNA can display corresponding phenotypes depends mainly on the types of mutations, the ratio of the specific type of mutation s relative to the total mutations and the lowest energy level that can maintain the normal functions of that organ/tissue. When the mtDNA mutations reach to certain threshold in a particular organ/ tissue, they can cause the functional pathogenesis of that organ/tissue. Due to the differences between fishes and human, there could be large differences in the modes of displaying mitochondrially-related diseases. In the future researches, we will apply the knowledge of mitochondrial heteroplasmy in fishes to the studies on fish genetics and find out the mutation locus closely related to the phenotypes and to economically important trails.

\section{Acknowledgement}

This study was supported by special fund for the Fundamental Research for Central Public-interest Scientific Institutions (Fresh Water Fishery Research Center, Chinese Academy of Fishery Sciences) (Grant \# 2011JBFB01 and 2013JBFM02), The natural science foundation of Jiangsu Province (Grant \# BK2011184) and National Natural Science Foundation (Grant \# 31200918)

\section{References}

1. Dong LN, Huang XR, Li YZ, Chen BG (2012) Sequence analysis of mitochondrial CO I and Cyt b gene of Nemipterus species in South China Sea. J Fish Sci Cn 2: $355-63$.

2. Cheng GB, Li SL, Xu DD, Xie BG, Gen Z, et al. (2012) Sequence analysis of 16 S rRNA and CoI gene fragment of Liza Haematocheila and Mugilcephalus. J Zhejiang Ocean University (Natural Sciences) 31: 103-5.

3. Zhang D, Lei GC, Gong C, Wang ZS (2012) Genetic diversity of Neosalanx taihuensis based on mitochondrial COI sequences. J Lake Sciences $24: 299-306$.

4. Guo XH, Liu SJ, Liu Q, Liu Y (2004) New Progresses on Mitochondrial DNA in Fish. Yi Chuan Xue Bao 31: 983-1000.

5. Imoto JM, Saitoh K, Sasaki T, Yonezawa T, Adachi J, et al. (2013) Phylogeny and biogeography of highly diverged freshwater fish species (Leuciscinae, Cyprinidae, Teleostei) inferred from mitochondrial genome analysis. Gene 514: 112-24.

6. Li J, Ye Y, Wu C, Qi P, Guo B, et al. (2013) Genetic variation of Mytilus coruscus Gould (Bivalvia: Mytilidae) populations in the East China Sea inferred from mtDNA COI gene Sequence. Biochem Syst Ecol 50: 30-8.

7. Grant WS, Liu M, Gao T, Yanagimoto T (2012) Limits of Bayesian skyline plot analysis of mtDNA sequences to infer historical demographies in Pacific herring (and other species). Mol Phylogenet Evol 65: 203-12.

8. Lu GQ, Li SF (1998) Advance in the study and application on fish mitochondrial DNA polymorphisms. J Fish Sci Cn 5: 94-9.

9. Kmiec B, Woloszynska M, Janska H (2006) Heteroplasmy as a common state of mitochondrial genetic information in plants and animals. Curr Genet 50: 149-59.

10. Taylor RW, Turnbull DM (2005) Mitochondrial DNA mutations in human disease. Nat Rev Genet 6: 389-402.

11. Goto Y, Nonaka I, Horai S (1990) A mutation in the tRNA (Leu) (UUR) gene associated with the MELAS subgroup of mitochondrial encephalomyopathies. Nature 348: 651-3.

12. Greaves LC, Taylor RW (2006) Mitochondrial DNA mutations in human disease. IUBMB Life 58: 143-51.

13. Chinnery PF, Howell N, Lightowlers RN, Turnbull DM (1997) Molecular pathology of MELAS and MERRF, the relationship between mutation load and clinical phenotypes. Brain 120: 1713-21.

14. Chang YS, Huang FL, Lo TB (1994) The complete nucleotide sequence and gene organization of carp (Cyprinuscarpio) mitochondrial genome. J Mol Evol 38: $138-55$.

15. Melton T (2004) Mitochondrial DNA heteroplasmy. Forensic Sci Rev 16: 2-20.

16. Clinnery PF, Howell N, Andrews RM, Turnbull D (1999) Clinical mitochondrial genetics. J Med Genet 36: 425-36.

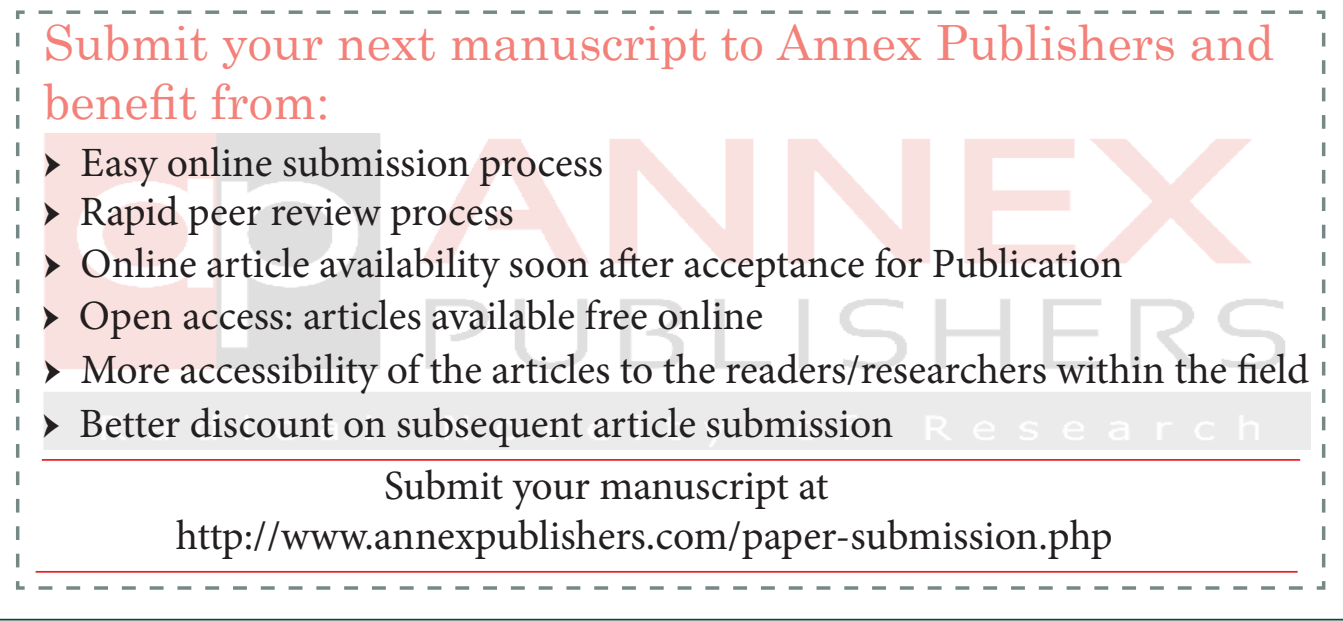

